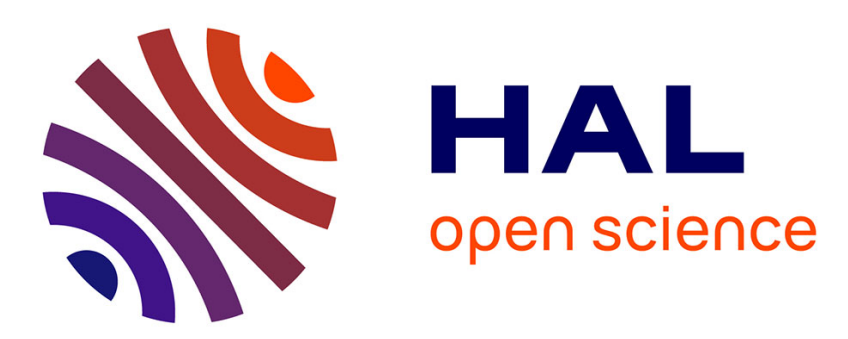

\title{
Astatine Standard Redox Potentials and Speciation in Acidic Medium
}

Julie Champion, C. Alliot, E. Renault, M. Mokili, M. Chérel, N. Galland, Gilles F Montavon

\section{- To cite this version:}

Julie Champion, C. Alliot, E. Renault, M. Mokili, M. Chérel, et al.. Astatine Standard Redox Potentials and Speciation in Acidic Medium. Journal of Physical Chemistry A, 2010, 114, pp.576-582. 10.1021/jp9077008 . in2p3-00450771

\section{HAL Id: in2p3-00450771 https://hal.in2p3.fr/in2p3-00450771}

Submitted on 27 Jan 2010

HAL is a multi-disciplinary open access archive for the deposit and dissemination of scientific research documents, whether they are published or not. The documents may come from teaching and research institutions in France or abroad, or from public or private research centers.
L'archive ouverte pluridisciplinaire HAL, est destinée au dépôt et à la diffusion de documents scientifiques de niveau recherche, publiés ou non, émanant des établissements d'enseignement et de recherche français ou étrangers, des laboratoires publics ou privés. 
Astatine standard redox potentials and speciation in acidic medium

J. Champion, ${ }^{1,3}$ C. Alliot, ${ }^{2}$ E. Renault, ${ }^{3}$ B.M. Mokili, ${ }^{1}$ M. Chérel, $^{2}$ N. Galland ${ }^{3} *$ and G. Montavon $^{1 *}$

1 Laboratoire SUBATECH, IN2P3/CNRS / EMN Nantes / Université de Nantes; 4 rue A. Kastler, BP 20722, 44307 Nantes Cedex 03, France

2 INSERM, U892, Université de Nantes, 9 Quai Moncousu 44093, Nantes Cedex 1, France

3 Laboratoire CEISAM, UMR CNRS 6230, Université de Nantes, 2 Rue de la Houssinière, BP 92208, 44322 Nantes Cedex 3, France

*Corresponding authors; G. Montavon: montavon@subatech.in2p3.fr. N. Galland: nicolas.galland@univ-nantes.fr. 


\section{ABSTRACT}

A combined experimental and theoretical approach is used to define astatine (At) speciation in acidic aqueous solution and answer the two main questions raised from literature data: does $\operatorname{At}(0)$ exist in aqueous solution and what is the chemical form of $\operatorname{At}(\mathrm{III})$, if it exists. The experimental approach considers that a given species is characterized by its distribution coefficient (D) experimentally determined in a biphasic system. The change in speciation arising from a change in experimental conditions is observed by a change in D value. The theoretical approach involves quasi-relativistic quantum chemistry calculations. The results show that At at the oxidation state 0 cannot exist in aqueous solution. The three oxidation states present in the range of water stability are $\operatorname{At}(-\mathrm{I}), \operatorname{At}(\mathrm{I})$ and $\operatorname{At}(\mathrm{III})$ and exist as $\mathrm{At}^{-}, \mathrm{At}^{+}$ and $\mathrm{AtO}^{+}$, respectively, in the 1 to $2 \mathrm{pH}$ range. The standard redox potentials of the $\mathrm{At}^{+} / \mathrm{At}^{-}$ and $\mathrm{AtO}^{+} / \mathrm{At}^{+}$couples have been determined, the respective values being $0.36 \pm 0.01$ and 0.74 $\pm 0.01 \mathrm{~V} v s$. NHE.

\section{INTRODUCTION}

Astatine (At), element 85, is below iodine in the periodic table of elements. One of its isotopes, ${ }^{211} \mathrm{At}$, is a promising candidate as a therapeutic agent in nuclear medicine. ${ }^{1,2}$ Although it is clear that much of the chemistry described for halogens is applicable to astatine, the chemical similarity between astatine and its nearest halogen neighbor, iodine, is not always obvious and At chemistry in aqueous solution is not well understood. In the presence of inorganic acids $\left(\mathrm{HNO}_{3}, \mathrm{HClO}_{4}, \mathrm{HCl}, \mathrm{H}_{2} \mathrm{SO}_{4}, p H=0-2\right)$ and in the range of potential where water is stable ( $E=-0.1$ to $1.2 \mathrm{~V}$ versus the Normal Hydrogen Electrode, vs. NHE), three different astatine species are generally proposed: one in reducing conditions $\left(\mathrm{Na}_{2} \mathrm{SO}_{3}\right),{ }^{3-5}$ one without additional reagents ${ }^{6}$ and one in oxidizing conditions $\left(\mathrm{K}_{2} \mathrm{Cr}_{2} \mathrm{O}_{7}\right.$ or $\left.\mathrm{Na}_{2} \mathrm{~S}_{2} \mathrm{O}_{8}\right) .{ }^{6,7}$ These three species, referred to as Species I, II and III respectively, correspond to 
three different oxidation states. Whereas the oxidation states $-\mathrm{I}, 0$ and $+\mathrm{I}$ were considered by Appelman, ${ }^{8}$ Visser et al. ${ }^{9}$ argued that At(0) could not exist in aqueous solution. Species I, II and III rather referred to At(-I), At(I) and At(III), respectively. By analogy to iodine, the oxidation states $-\mathrm{I}$ and $+\mathrm{I}$ might correspond to $\mathrm{At}^{-}$and $\mathrm{At}^{+}$species, respectively. ${ }^{6}$ Finally, for the oxidation state III, several forms have been proposed, $\mathrm{At}^{3+}$ and $\mathrm{AtO}^{+}$most notably. ${ }^{6,7,9}$

These discrepancies are explained because astatine is one of the most difficult elements to investigate from a chemist's point of view. There are no stable isotopes of astatine, its longest-lived isotope having a half-life of $8.3 \mathrm{~h}$. Since astatine has no long-lived nuclides, all investigations were derived from radiochemical studies at ultra-trace concentrations, typically between $10^{-12}$ and $10^{-15} \mathrm{~mol} / \mathrm{L}$. Thus, no spectroscopic tools could be used to identify unambiguously the species formed. The chemical forms of astatine are usually deduced from its behavior in given conditions with respect to the behavior of expected model compounds. In this work, a combined experimental and theoretical approach is used to define the astatine redox potentials in acidic non complexing medium with the aim of answering the two questions previously raised: does $\operatorname{At}(0)$ exist in aqueous solution and what is the chemical form of At(III), if it exists ? The theoretical approach is based on quasi-relativistic quantum chemistry calculations and deals with the existence of $\mathrm{At}_{2}$ species for the oxidation state At(0). The experimental approach corresponds to those of Meyer et al. ${ }^{4}$ and Cavallero et al.., ${ }^{3}$ i.e. a given species is characterized by its distribution coefficient experimentally determined in liquid-liquid $(D)$ or solid-liquid $(K d)$ biphasic systems. The change in speciation arising from a change in experimental conditions is observed by a change in the distribution coefficient. Unlike previous studies, we present a quantitative analysis of the experimental data based on equilibrium reactions, to identify the species formed and derive the thermodynamic parameters. 


\section{EXPERIMENTAL AND THEORETICAL PROCEDURES}

\section{(A) Materials and analytical tools}

\section{Chemical}

All commercially available products were of analytical grade or superior. Stock suspensions of the ion exchange resins Dowex-50WX8 (200 mesh, Sigma Aldrich) were prepared in water after a pre-treatment of 5-6 hours with $\mathrm{HClO}_{4}(5 \mathrm{~mol} / \mathrm{L})$ to eliminate impurities.

\section{Production and extraction of astatine-211}

Astatine-211 was prepared at the CEMTHI cyclotron in Orleans (France) according to the nuclear reaction ${ }^{209} \mathrm{Bi}(\alpha, 2 \mathrm{n}){ }^{211}$ At. The bismuth target was irradiated for two hours by a $28 \mathrm{MeV}$ alpha external beam with an average beam current of $2 \mu \mathrm{A} .^{10}$ The $\mathrm{Bi}$ deposit was dissolved in the presence of $10.6 \mathrm{~mol} / \mathrm{L} \mathrm{HNO}_{3}$ (4 fold $0.5 \mathrm{~mL}$ ). The active solution was then evaporated and the astatine residue dissolved in $3 \mathrm{~mL}$ of $\mathrm{HNO}_{3}(4.8 \mathrm{~mol} / \mathrm{L})$. Selective extraction of astatine from the acidic medium was carried out by liquid-liquid extraction with diisopropylether (DIPE). ${ }^{11}$ The aqueous solution was mixed in a small decanter with $0.5 \mathrm{~mL}$ DIPE for 10 min. After phase separation, the aqueous phase was again brought into contact with a fresh DIPE solution. Astatine back extraction was carried out in a two step procedure described by Alliot et al. ${ }^{12}$ Due to the solubility of nitric acid in DIPE, traces of $\mathrm{Bi}$ and $\mathrm{Cu}$ were co-extracted and eliminated by mixing for 5 minutes the organic phase with $1 \mathrm{~mL}$ of an aqueous phase containing $1 \mathrm{~mol} / \mathrm{L} \mathrm{HCl}$. This step was repeated two times. Astatine was then back extracted in $0.1 \mathrm{~mol} / \mathrm{L} \mathrm{NaOH}$ to get $500 \mu \mathrm{L}$ of a solution with a specific volumic activity close to $1 \mathrm{MBq} / \mathrm{mL}$. 


\section{$\underline{\text { Analytical tool }}$}

Astatine purity was controlled by gamma ray spectrometry with a high purity germanium (HPGe) detector. The full widths at half maximum (FWMH) were $1.04 \mathrm{keV}$ at $122 \mathrm{keV}$ (with cobalt-57 measurement) and $1.97 \mathrm{keV}$ at $1332 \mathrm{keV}$ (with cobalt-60 measurement). The activity was measured with this gamma ray detector in a suitable geometry previously calibrated with standard gamma sources. The activity of the stock astatine solution was measured on both the X-rays from ${ }^{211} \mathrm{Po}$ and ${ }^{211}$ At and $\gamma$-rays at $687.00 \mathrm{keV}$ from ${ }^{211}$ At. $^{13}$

${ }^{211}$ At distribution in solid-liquid or liquid-liquid systems (see experimental methodology) was performed by liquid scintillation counting using a Packard 2550 TR/AB Liquid Scintillation analyzer with the Ultima Gold LLT scintillation liquid. The quenching arising from the different solvents was taken into account for determining astatine activity (A) according to the following relation:

$$
A=A_{\text {mes. }} \times\left(8.10^{-10} \times t S I E^{3}-2.10^{-6} \times t S I E^{2}+0.0013 \times t S I E+0.7228\right) \quad \text { eq.(1) }
$$

Where $A_{\text {mes }}$ is the activity measured by liquid scintillation and $t S I E$ is a parameter defined by the apparatus for counting efficiency determination.

Fisherbrand type electrode freshly calibrated against dilute standard $p H$ buffers $(p H 1-10$, Merck) were used to determine the $p H$. The potential $(E)$ of aqueous solutions was measured using a Pt combined redox electrode (Metrohm type) calibrated against redox buffer $\left(\mathrm{Fe}(\mathrm{SCN})_{6}{ }^{3-} / \mathrm{Fe}(\mathrm{SCN})_{6}{ }^{4-}, 215 \mathrm{mV} / \mathrm{Pt} / \mathrm{SCE}\right.$, Radiometer Analytical).

\section{(B) Experimental methodologies}

All solutions were prepared using Milli-Q water and all experiments were conducted in airconditioned laboratories $\left(22 \pm 3^{\circ} \mathrm{C}\right)$. Perchlorate medium was used to avoid any complexing with cationic forms of astatine. At least three experiments were performed in parallel. The average values are given with uncertainties corresponding to a confidence interval of 95\%. 


\section{Preparation of astatine species}

In accordance with the literature, Species I was prepared in $0.1 \mathrm{~mol} / \mathrm{L} \mathrm{Na}_{2} \mathrm{~S}_{2} \mathrm{O}_{3}$ and $\mathrm{HClO}_{4}$ $(E \sim 0.2 \mathrm{~V} \text { vs. NHE)})^{5}$ Species II in $0.1 \mathrm{~mol} / \mathrm{L} \mathrm{HClO}_{4}$ concentration $(E \sim 0.5 \mathrm{~V} \text { vs. NHE})^{6}$ and Species III with a mixture of $510^{-3} \mathrm{~mol} / \mathrm{L} \mathrm{K}_{2} \mathrm{Cr}_{2} \mathrm{O}_{7}$ and $0.1 \mathrm{~mol} / \mathrm{L} \mathrm{HClO}_{4}(E \sim 1 \mathrm{~V}$ vs. NHE). ${ }^{7,14}$ The oxidation of Species I was studied in the biphasic water/toluene system and the potential of the solution was varied using the $\mathrm{SO}_{3}{ }^{2-} / \mathrm{SO}_{4}{ }^{2-}$ redox couple $\left(\left[\mathrm{SO}_{\mathrm{x}}{ }^{2-}\right]_{\text {total }}=0.1 \mathrm{~mol} / \mathrm{L}\right)$ in $0.1 \mathrm{~mol} / \mathrm{L} \mathrm{HClO}_{4}{ }^{3}$ In the case of the oxidation of Species II, the ion exchanger resin Dowex-50WX8 was used and the $E$ variation was realized using the $\mathrm{Fe}^{3+} / \mathrm{Fe}^{2+}$ redox couple $\left(\left[\mathrm{Fe}^{\mathrm{n}+}\right]_{\text {total }}=0.1 \mathrm{~mol} / \mathrm{L}\right)^{15}$ at different $\mathrm{HClO}_{4}$ concentrations (from $10^{-2}$ to $0.3 \mathrm{~mol} / \mathrm{L}$ ).

\section{Experimental approach}

Irrespective of the method used, the $p H$ and the potential of the solutions were systematically measured at equilibrium.

\section{Biphasic solid-liquid system}

For the solid/liquid system, an aliquot of the ion exchanger resin stock suspension ( $0.25 \mathrm{~g})$ was mixed in polypropylene tubes with the bulk solution $(5 \mathrm{~mL})$ to get a solid-to-liquid ratio (S/L) of $50 \mathrm{~g} / \mathrm{L}$. After equilibration of the system, astatine (about $1000 \mathrm{~Bq}$ ) was added. Kinetic measurements showed that the time required to reach equilibrium was less than $2 \mathrm{~h}$. The distribution coefficient was defined as:

$$
K d=\frac{A_{\text {tot }}-A_{\text {sol }}}{A_{\text {sol }}} \frac{L}{S}
$$

where $A_{\text {tot }}$ is the total activity in the suspension, $A_{\text {sol }}$ is the activity measured in the solution, $L$ is the volume of the liquid phase and $S$ is the dried mass of resin. The separation between solid and liquid phases was achieved by centrifugation (500 g). $A_{t o t}$ was measured directly in 
the sample to avoid taking into account astatine sorption on the walls. The presence of the resin was shown not to affect the counting efficiency. ${ }^{16}$

\section{Biphasic liquid-liquid system}

Astatine behavior was studied in biphasic liquid/liquid systems with toluene. ${ }^{16} 5 \mathrm{~mL}$ of organic and aqueous phases were brought into contact in Pyrex tubes. After equilibration, an aliquot of astatine stock solution (1000 Bq) was added and the tubes were shaken for $2 \mathrm{~h}$. This time proved to be sufficient to achieve an equilibrium distribution of At between the two phases. After phase separation, aliquots of the aqueous and organic phases were withdrawn to derive the distribution coefficient $D$ :

$$
D=\frac{V_{a q} \times A_{o r g}}{V_{\text {org }} \times A_{a q}}
$$

$V_{\text {org }}$ and $V_{a q}$ represent the volume of the given phase. $A_{\text {org }}$ and $A_{a q}$ define the astatine activities measured in the organic and aqueous phases, respectively.

\section{Modeling}

The CHESS program ${ }^{17}$ was used to simulate the reactions occurring in the biphasic system. An input file describing the experimental conditions (medium composition, $p H, E$ and temperature) is created and the species distribution at equilibrium is calculated using the thermodynamic database introduced in CHESS. This latter includes three kinds of data:

1. The reactions describing astatine distribution between aqueous and organic/solid phases; the extraction/sorption processes were considered as a simple partitioning. ${ }^{16}$

2. The redox reactions; they are the subject of this work and they were studied by following astatine speciation $(D, K d)$ with the potential at a given $p H$. 
3. The equilibria describing the interaction between the species and the components of the system, i.e. water (acid-base reactions, hydrolysis) or complexing agents in the case of cation.

The equilibrium constants associated with the reactions were determined following a threestep procedure. The equilibrium considered was first introduced in CHESS and the associated parameter was adjusted to get the best "visual" agreement between the experiment and the modeling. The main equilibria occurring in the experimental conditions were then considered to derive an analytical expression, which was then used to fit the data with Sigma Plot software $^{18}$ using the Marquardt-Levenberg algorithm (version 2.0, Jandel Co.). Uncertainties associated with the fitting parameters were determined by the software. The parameters obtained were then introduced in the CHESS code for validation. All the equilibrium constants in the database were extrapolated at zero ionic strength using the Truncated Davies equation. $^{19}$

\section{(C) Computational methodology}

Relativistic effects on the structure of molecules that contain heavy elements such as astatine can be comparable or larger than electron correlation effects. It is widely known that the inclusion of spin-orbit interactions as well as scalar relativistic effects are necessary for calculations on such species. The most reliable results can be obtained from the wave functions obtained from relativistic Hamiltonian. This all-electron approach is computationally very demanding. Using two-component relativistic effective core potentials (RECPs) or pseudo potentials (PPs), which contain scalar and spin-orbit potentials, is an efficient alternative due to the significant reduction in the number of basis functions and the simple form of the Hamiltonian employed. As illustrated recently on molecules containing astatine, ${ }^{20,21}$ approximate calculations based on RECPs or PPs are known to successfully yield 
results that are very close to the all-electron results without introducing any empirical parameters. Application of density functional theory (DFT) appears particularly attractive for heavy-element systems due to the computational expediency and the implicit inclusion of electron correlation effects. The two-component SO-DFT approach implemented in the NWChem programs package, ${ }^{22}$ which uses RECPs or PPs including spin-orbit terms, has been successfully used to investigate relativistic effects on molecules containing halogen elements. ${ }^{23-25}$

Gas-phase properties (energy, geometry, vibrational frequencies) of $\mathrm{X}^{-}$and $\mathrm{X}_{2}(\mathrm{X}=\mathrm{Br}, \mathrm{I}$ and At) species have been determined by B3LYP ${ }^{26-28}$ density functional calculations following the SO-DFT framework. We used the small-core (25 valence electrons) spin-dependent relativistic PPs together with the large aug-cc-pVQZ-PP basis set generated by the Stuttgart/Cologne group. ${ }^{20,29}$ The relativistic effects in $\mathrm{Cl}^{-}$and $\mathrm{Cl}_{2}$ species were neglected and their gas-phase properties were determined at B3LYP/aug-cc-pVQZ ${ }^{30}$ level of theory. Gibbs free energies of aqueous solvation were computed for all species using the polarisable continuum model (PCM) implemented in the Gaussian 03 program package. ${ }^{31}$ We selected the conductor-like formulation, $\mathrm{CPCM},{ }^{32,33}$ since this model used in conjunction with the UAHF cavity model yields accurate solvation free energies at a very low computational cost. $^{34}$ The UAHF cavities were built up using the united atom topological model applied on radii optimized for the HF/6-31G(d) level of theory. ${ }^{31,35}$ However, at present no radius for astatine element is included in the UAHF model. We propose to define an astatine radius coherent with the rest of the radii included in the UAHF model, in particular with the trend followed by the halogen UAHF radii. UAHF basic radii were compared for $\mathrm{F}, \mathrm{Cl}, \mathrm{Br}$ and I atoms against different sets of radii : ab initio computed atomic radii, ${ }^{36}$ recently revisited empirical covalent radii $^{37}$ and finally a set of van der Waals radii. ${ }^{38}$ The best linear relationship was obtained with the van der Waals radii gathered by Truhlar et al. (the 
associated correlation coefficient is 0.999 and the standard error on UAHF radii is $0.02 \AA){ }^{38}$ Using the van der Waals radii reported for At, we extrapolated a value of $2.41 \AA$ that we recommend for the astatine UAHF basic radius.

In the CPCM model, the solvation free energy is partitioned in different terms. The most important one is the electrostatic term, some other terms are usually negligible ${ }^{34}$ while the dispersion and repulsion terms are unavailable for astatine. Furthermore, the sum of nonelectrostatic terms is generally weak with respect to the electrostatic term, especially for charged species, due to the cancellation of different contributions. ${ }^{39}$ Hence, only the electrostatic term was retained in CPCM computations. For $\mathrm{X}^{-}$and $\mathrm{X}_{2}(\mathrm{X}=\mathrm{Br}, \mathrm{I}$ and $\mathrm{At})$ species, the solvation free energies were determined at scalar-relativistic HF level of theory using the small core PPs and aug-cc-pVDZ-PP basis set generated by the Stuttgart/Cologne group. ${ }^{20,29}$ In the case of $\mathrm{Cl}^{-}$and $\mathrm{Cl}_{2}$ species, we retained the HF/aug-cc-pVDZ ${ }^{30}$ level of theory. Geometries of the molecular species were optimized both in the gas-phase and in the presence of solvent.

\section{RESULTS}

\section{(A) Species I / Species II}

This part concerns the oxidation of Species I, which produces Species II. In agreement with what is reported in the literature, ${ }^{6,40}$ the distribution coefficients of the two species in toluene are different (Figure 1). At first, Species I (i.e. At(-I)) is not extracted by the organic solvent from a solution of $\mathrm{NaClO}_{4}$ and $\mathrm{Na}_{2} \mathrm{~S}_{2} \mathrm{O}_{3}$ (both $0.1 \mathrm{~mol} / \mathrm{L}$ ) with the $p H$ varying between 1 and 3.5. This indicates the presence of one species, corresponding most probably to $\mathrm{At}^{-}$according to the trend observed within the halogen series: the heavier the halogen, the more acidic it is (see Table 1). By contrast, Species II presents a significant affinity for toluene with a mean $D$ value of 8 . This species is known to interact with anions like halogens to form $\mathrm{AtX}_{\mathrm{m}}{ }^{\mathrm{n}-}$ 
species. ${ }^{16,41}$ Such a reaction could occur as well with water leading to hydroxo complexes and/or with the anions introduced in the solution to fix the potential $\left(\mathrm{SO}_{3}{ }^{2-}, \mathrm{SO}_{4}{ }^{2-}\right)$. However, the extraction of Species II in toluene from a solution of $0.1 \mathrm{~mol} / \mathrm{L} \mathrm{NaClO}_{4}$ with the $p H$ varying between 1 to 2.5 indicated no interaction with water, since the partitioning in organic phase is unchanged. The interaction with $\mathrm{SO}_{4}{ }^{2-}$, the compound becoming the majority compound as E increases, is also not likely. As shown in Figure 2, an interaction (or a change in $D$ value) is observed only for sulfate concentrations above $3.10^{-3} \mathrm{~mol} / \mathrm{L}$, whereas the change from Species I to Species II is studied for $\left[\mathrm{SO}_{4}{ }^{2-}\right]<1.10^{-3} \mathrm{~mol} / \mathrm{L}$.

The change from one species to the other with increasing aqueous solution potential is characterized by an inflexion point indicating an apparent redox potential of $0.36 \pm 0.01 \mathrm{~V} v s$. NHE (see Figure 1) for the Species I/Species II couple. This is coherent with the values generally reported in the literature and ranging from 0.3 to $0.35 \mathrm{~V}$ (vs. NHE) for different media $\left(0.1 \mathrm{~mol} / \mathrm{L} \mathrm{NaNO}_{3}, 0.1 \mathrm{~mol} / \mathrm{L} \mathrm{HClO}_{4}\right.$ and $\left.0.1 \mathrm{~mol} / \mathrm{L} \mathrm{KNO}_{3}\right){ }^{3,8,42}$ It is important to note that these $E$ values were obtained for different $p H$ conditions. This shows that the redox reaction does not involve protons. The experimental curve was modeled considering the two main equilibria found in the literature, i.e. the change from At to At (dashed line in Figure 1) or the change from $\mathrm{At}^{-}$to $\mathrm{At}^{+}$(solid line in Figure 1). The two equilibria involve different numbers of exchanged electrons. This is reflected by the slope of the curve: the slope is greater for an increasing number of exchanged electrons. The best agreement between experiment and modeling is clearly obtained considering that two electrons are exchanged.

The hypothesis that an $\operatorname{At}(0)$ species is formed through the oxidation of $\mathrm{At}^{-}$was theoretically investigated using quantum chemistry calculations. At can be reduced from its oxidized form, $\mathrm{At}_{2}$, via the following 2-electron half reaction:

$$
\mathrm{At}_{2}(\mathrm{aq})+2 \mathrm{e}^{-}(\mathrm{g}) \square \quad 2 \mathrm{At}^{-}(\mathrm{aq})
$$


The standard free energy change of reaction (4), $\Delta G_{s}^{*}$, is related to the absolute standard reduction potential via the Nernst equation:

$$
E^{\circ}=-\frac{\Delta G_{s}^{*}}{n F}
$$

where $n$ is the number of electrons transferred ( $n=2$ in this case) and $F$ is the Faraday constant $(96485 \mathrm{C} / \mathrm{mol})$. As Scheme 1 shows, $\Delta G_{s}^{*}$ can be calculated from its components by introducing a thermodynamic cycle:

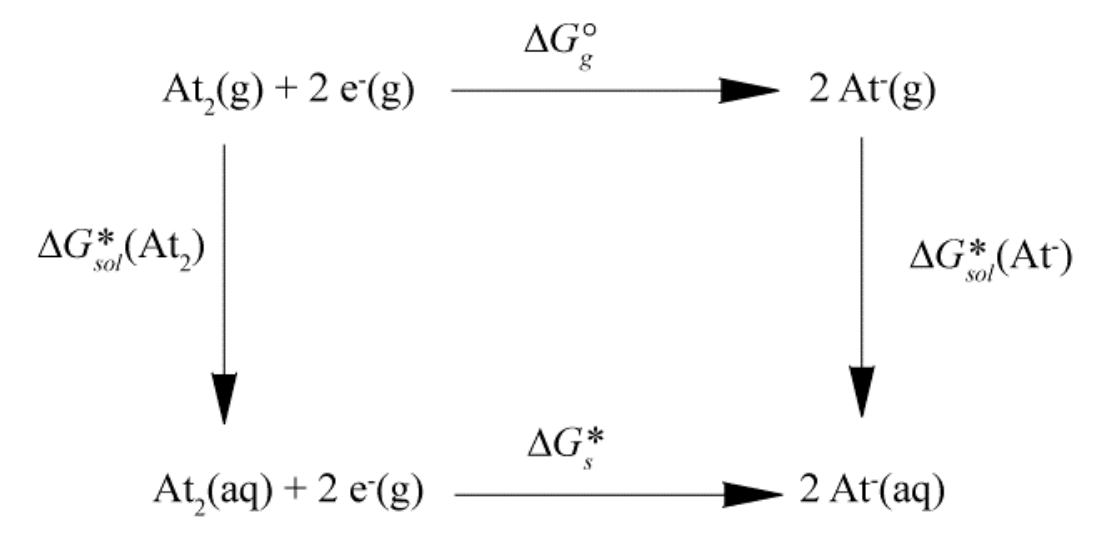

\section{Scheme 1}

$$
\Delta G_{s}^{*}=\Delta G_{g}^{\circ}+2 \Delta G_{s o l}^{*}\left(\mathrm{At}^{-}\right)-\Delta G_{s o l}^{*}\left(\mathrm{At}_{2}\right)+\Delta n \Delta G^{\circ \rightarrow *}
$$

where $\Delta G_{g}^{\circ}$ is the change of free energy in the gas-phase; $\Delta G_{\text {sol }}^{*}\left(\mathrm{At}_{2}\right)$ and $\Delta G_{\text {sol }}^{*}\left(\mathrm{At}^{-}\right)$are solvation free energies of $\mathrm{At}_{2}$ and $\mathrm{At}^{-}$in water, respectively; $\Delta G^{\circ \rightarrow *}$ is the correction for the change in standard state from $1 \mathrm{~atm}$. for gas-phase calculations to $1 \mathrm{~mol} / \mathrm{L}$ for solution phase; $\Delta n$ is the change of moles ( +1 in this case). For the free electron, we have followed the electron convention based on Boltzmann statistics (EC-B), although Bartmess ${ }^{43}$ has pointed out that a more correct treatment of the electron uses Fermi-Dirac statistics (EC-FD). To allow comparison with experiment, it is necessary to calculate the standard reduction potential of $\mathrm{At}_{2}$ relative to NHE. Therefore, the absolute value of the standard reduction potential of NHE is required. In the present work, we have used for NHE the value of $4.28 \mathrm{~V}$ corresponding to the EC-B convention. ${ }^{44} E^{\circ}$ has been calculated as $0.26 \mathrm{~V}$ vs. NHE. It is 
worth noting that, using EC-FD convention, we obtained a value of $0.26 \mathrm{~V}$ for $E^{\circ}$ as the $\mathrm{At}_{2}$ and NHE absolute reduction potentials are equally affected by the change in electron convention.The result obtained for $\mathrm{Cl}_{2} / \mathrm{Cl}^{-}, \mathrm{Br}_{2} / \mathrm{Br}^{-}$and $\mathrm{I}_{2} / \mathrm{I}^{-}$couples give a good trend but the calculations are systematically above the standard potentials with respect to the tabulated values (see Table 2). ${ }^{45}$

One can argue that the estimation of $\mathrm{At}_{2}$ reduction potential can be improved using a more sophisticated treatment for the computation of the gas-phase $\Delta G_{g}^{\circ}$. Recently, van Wüllen et $a .^{21}$ reported for At and $\mathrm{At}_{2}$ species their electronic affinity and spectroscopic constants, respectively, determined by two-component all-electron calculations with the sixth-order Douglas-Kroll (DK6) Hamiltonian. ${ }^{21}$ The $\Delta G_{g}^{\circ}$ value estimated from the reported B3LYP results leads to an $\mathrm{At}_{2}$ standard reduction potential of $0.25 \mathrm{~V} v \mathrm{v}$. NHE. This value is very close to our value of $0.26 \mathrm{~V}$ vs. NHE, showing the good reliability of the calculated $\Delta G_{g}^{\circ}$ value. A successful alternative method for computing reduction potentials involves consideration of a balanced reaction:

$$
X_{2}(a q)+2 Y^{-}(a q) \square \quad Y_{2}(a q)+2 X^{-}(a q) \text { eq.(7) }
$$

$\mathrm{X}$ and $\mathrm{Y}$ are both halogen elements and the reaction conserves the number of charged and neutral species.

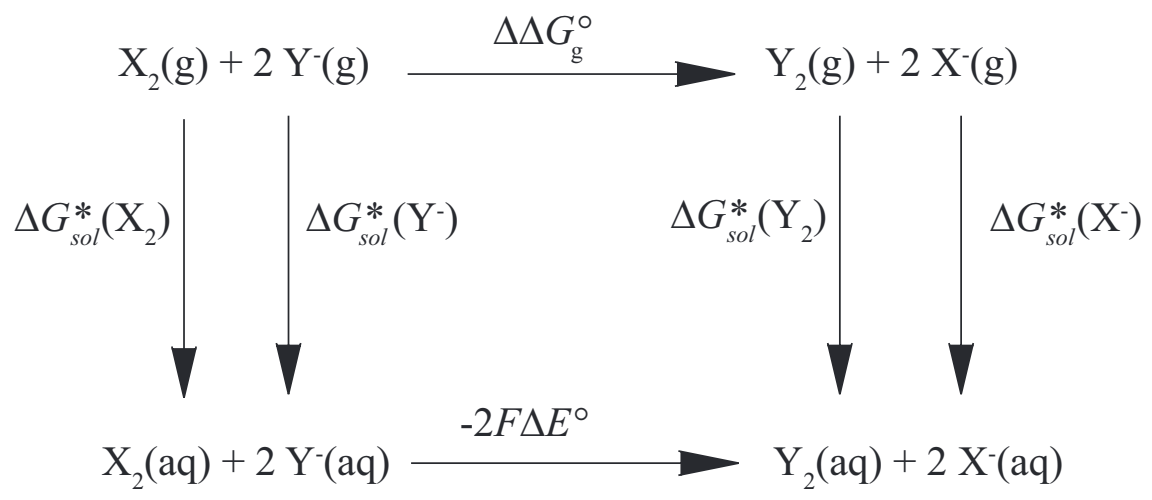

Scheme 2 
Following the decomposition pathway displayed in Scheme 2, the prediction of the difference between reduction potentials, $\Delta E^{\circ}$, associated with reaction (7) could benefit from (i) bondby-bond errors in electron correlation/relativistic contributions which partially cancel in the computed gas-phase free energy, $\Delta \Delta G_{g}^{\circ}$, (ii) in pairs, cancellations of errors associated with the calculations of ionic and neutral solvation free energies, $\Delta G_{\text {sol }}^{*}$. For example, using our computational methodology, the differences between the standard reduction potentials of $\mathrm{I}_{2}$ and $\mathrm{Br}_{2}, \mathrm{I}_{2}$ and $\mathrm{Cl}_{2}$ and finally $\mathrm{Br}_{2}$ and $\mathrm{Cl}_{2}$ are respectively $-0.44,-0.76$ and $-0.31 \mathrm{~V}$ (see Table 2). These values compare very well with the $-0.47,-0.78$ and $-0.31 \mathrm{~V}$ values obtained from the tabulated standard reduction potentials of $\mathrm{I}_{2}, \mathrm{Br}_{2}$ and $\mathrm{Cl}_{2}{ }^{45}$ The errors in computed $\Delta E^{\circ}$ do not exceed $0.03 \mathrm{~V}$.

The differences between the $\mathrm{At}_{2}$ reduction potential and those of $\mathrm{I}_{2}, \mathrm{Br}_{2}$ and $\mathrm{Cl}_{2}$ were then computed. Adding the value of the tabulated standard reduction potentials of $\mathrm{I}_{2}, \mathrm{Br}_{2}$ and $\mathrm{Cl}_{2}$, yields respectively the following values for the $\mathrm{At}_{2}$ standard reduction potential: $0.17,0.19$ and $0.19 \mathrm{~V}$ vs. NHE. Note that if $\mathrm{At}_{2}$ is considered as a gas-phase species in reactions (4) and (7), the computed reduction potential is lowered as the solvation free energy of $\mathrm{At}_{2}$ was not taken into account.

\section{(B) Species II / Species III}

This part deals with the oxidation of Species II that leads to Species III. It was studied as a function of $p H(0-2)$ and $E(0.5-0.9 \mathrm{~V})$. The curves are show in Figure 3. In agreement with the related experiments performed by HPLC, ${ }^{3,4}$ the two species present different sorption affinities for the exchanger: the $K d$ values amount to 30 and 110 for Species II and Species III, respectively. As for the liquid/liquid system (Species I/Species II, see part (A)), the non sensitivity of distribution coefficients with $\mathrm{pH}$ indicates in each case the presence of one 
given astatine species as already observed in a previous work. ${ }^{16}$ This observation is coherent with the work of Alliot et al., ${ }^{12}$ where the hydrolysis of species III was shown to start only above $p H=2$. However, it disagrees with the work of Milanov et al. ${ }^{46,47}$ Electromobility measurements performed in conditions where Species III prevails have shown a decrease in the mobility as the $\mathrm{pH}$ varied between 1 and 2, suggesting the formation of a probable neutral species. However, as discussed by the authors, they found the constant derived from the experimental data overestimated and complementary results were necessary. Based on these considerations, no reaction with water was considered in the modeling. All experimental curves were satisfactorily modeled considering that 2 electrons are exchanged between the two species.

The redox reaction depends on the $p H$, i.e. the apparent potential determined at the inflexion point of the curves decreases as the $p H$ increases (see Figure 4). It varies from 0.60 to $0.70 \mathrm{~V}$ for $\mathrm{pH}$ increasing from 0.65 to 2.04 . The standard potential extrapolated at $p H=0$ is $0.74 \pm 0.01 \mathrm{~V}$. This value appears coherent with those published in the literature. ${ }^{3,41}$

\section{DISCUSSION}

In acid and slightly reducing conditions, At ${ }^{-}$is the expected chemical form of At(-I) according to the chemistry of its related compounds, the halogens. Its existence is furthermore coherent with respect to At(-I) behavior: it reacts as a nucleophilic agent, ${ }^{48}$ it coprecipitates with insoluble iodide compounds ${ }^{6}$ and it interacts with an anion exchange resin as expected. ${ }^{5}$ The negative charge of the species was also experimentally evidenced by electromobility measurements. ${ }^{49}$ In the present paper, we also suggest that the HAt species is not likely to exist at $p H>1$. All these considerations lead us to conclude that the starting assumption to consider the existence of $\mathrm{At}^{-}$(Species I) in acidic and reducing conditions is reliable. 
One of the most discussed species in the literature is the one existing in slightly acidic conditions, Species II. An attempt to characterize the species by mass spectrometry was made, but no conclusions could be drawn. ${ }^{50}$ Both $\operatorname{At}(0)$ and $\operatorname{At}(\mathrm{I})$ forms are proposed. ${ }^{8,41}$ The oxidation of $\mathrm{At}^{-}$to form Species II is $\mathrm{pH}$-independent and the present study reveals for the first time that two electrons are exchanged. Considering our experimental results, the existence of $\operatorname{At}(0)$ would be in agreement provided that $\operatorname{At}(0)$ exists as $A_{2}$. Such a diatomic species is however unlikely to exist considering the range of astatine concentrations studied. ${ }^{41}$ Furthermore, our investigations using quantum chemistry methods show that the expected standard potential of the $\mathrm{At}_{2} / \mathrm{At}^{-}$couple, about $0.18 \mathrm{~V}$ vs. NHE, could not correspond to the measured redox potential, $0.36 \pm 0.01 \mathrm{~V}$. Hence, the exchange of two electrons rather shows the formation of $\mathrm{At}(\mathrm{I})$. Its presence as the cationic species $\mathrm{At}^{+}$will notably explain the ability of the species to react with halogen anions to form $\mathrm{AtX}_{\mathrm{m}}{ }^{\mathrm{n}-}$ species. ${ }^{9}$ These species were observed by mass spectrometry ${ }^{51}$ and thermochromatography. ${ }^{5}$ Such complexation reactions were as well evidenced with $\mathrm{SO}_{4}{ }^{2-}$ in the present study and with $\mathrm{SCN}^{-16}$. As discussed by Alliot et al., ${ }^{12} \mathrm{At}(\mathrm{I})$ extraction in organic solvents could be explained by the extraction of ion pairs AtX, where X represents a counter anion present in the aqueous phase.

In acidic conditions and in the presence of dichromate, there is no doubt about the presence of an other "metallic" compound. It holds a positive charge, as evidenced by electromobility experiments, ${ }^{49}$ and it forms complexes with anions. ${ }^{52-55}$ The nature of Species III remains however unknown and several forms are proposed: $\mathrm{At}^{+}, \mathrm{AtO}^{+}$and $\mathrm{At}^{3+} \cdot{ }^{5-9}$ Some authors have attempted to identify the nature of the cationic form by comparing its behavior with inorganic sorbents with that of model cations. For example, Rössler et al. ${ }^{5}$ proposed $\mathrm{At}^{+}$considering the difference in retention volumes obtained by HPLC on Aminex A7 cation-exchange resin between Species III and $\mathrm{Tl}^{+}$. On the other hand, Milanov et al. ${ }^{46}$ showed a complete different behavior between Species III and $\mathrm{Tl}^{+}$when studying sorption on titanium dioxide. The 
different conclusions show the limit of the method used, i.e. to identify the nature of the species by looking qualitatively at its behavior. ${ }^{41,46}$ In the present work, our approach is different since astatine behavior is modeled. On the one hand, considering that (i) $\mathrm{At}^{+}$is the species present in slightly acidic conditions, (ii) two electrons are exchanged with $\mathrm{At}^{+}$and (iii) the variation in the apparent potential with $p H$, one can safely exclude the presence in solution of $\mathrm{At}^{3+}$ as Species III. On the other hand, all the experimental data can be described with a given set of parameters when the species $\mathrm{AtO}^{+}$is considered.

\section{CONCLUSIONS}

All the results presented in this paper show that At at the oxidation state 0 cannot exist in aqueous solution. Three oxidation states evidenced in the range of water stability ( $E=-0.1$ to 1.2 V vs. NHE) and in the $p H$ range 1.0-2.0 are At(-I), At(I) and At(III) and correspond to the $\mathrm{At}^{-}, \mathrm{At}^{+}$and $\mathrm{AtO}^{+}$chemical forms, respectively. The standard potentials of the associated redox reactions are:

$$
\begin{array}{lll}
A t^{+}+2 e^{-} \square \quad t^{-} & 0.36 \pm 0.01 \mathrm{~V} v s . \mathrm{NHE} \\
\mathrm{AtO}^{+}+2 \mathrm{H}^{+}+2 e^{-} \square & \mathrm{At}^{+}+\mathrm{H}_{2} \mathrm{O} & 0.74 \pm 0.01 \mathrm{~V} \text { vs. NHE }
\end{array}
$$

The formation of stable $\mathrm{At}^{+}$and $\mathrm{AtO}^{+}$cationic forms in aqueous solution confirm the more "metallic" character of At as compared to the other halogens.

\section{ACKNOWLEDGMENTS}

The authors would like to thank the French National Research Agency (ANR, JCJC06_137852), the "Cancéropôle du Grand Ouest” and the European Commission (TARCC project) for financial support, CEMTHI for the production of 211-At, and CNRS and the "Region Pays de la Loire” for the grant allocated to Julie Champion. The authors 
gratefully acknowledge IDRIS (Institut du Développement et des Ressources en Informatique), CINES (Centre Informatique National de l'Enseignement Supérieur) and CCIPL (Centre de Calcul Intensif des Pays de la Loire) for grants of computer time. 


\section{Figures and tables}

Figure 1: Study of the oxidation of Species I in a biphasic aqueous/toluene system. The experimental curve was modeled considering the two main equilibria considered in the literature, i.e. going from $\mathrm{At}^{-}$to $\mathrm{At}^{+}$(solid line) or going from $\mathrm{At}^{-}$to At (dashed line).

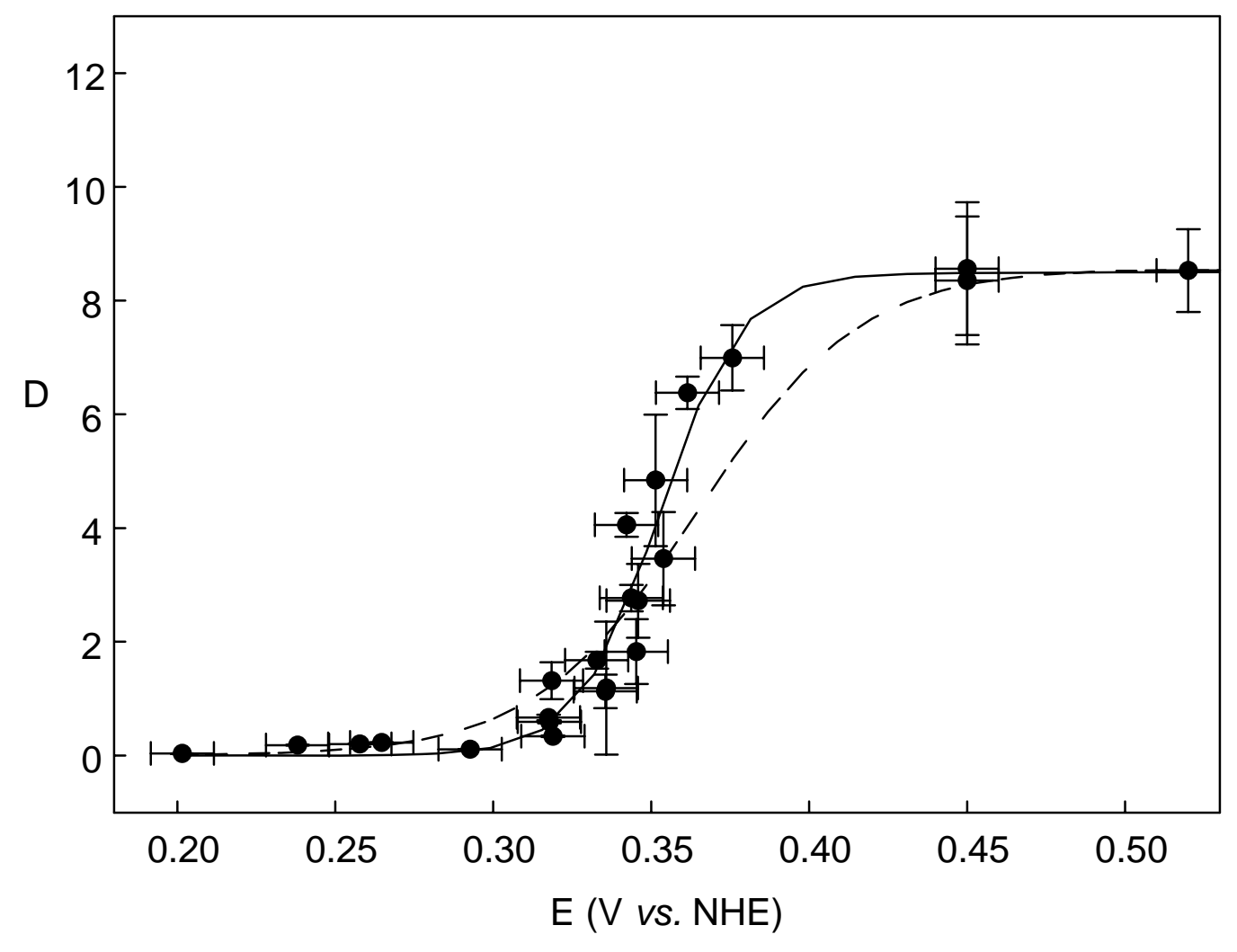


Figure 2: Study of the interaction between Species II and $\mathrm{SO}_{4}{ }^{2-}$ in a biphasic aqueous/toluene system. The distribution coefficient $(D)$ is plotted as a function of $\mathrm{SO}_{4}{ }^{2-}$ concentration in the $\mathrm{NaClO}_{4}$ aqueous solution $(0.1 \mathrm{~mol} / \mathrm{L}, p H=1)$. The line corresponds to the calculation performed with CHESS using the parameters given in Table 3.

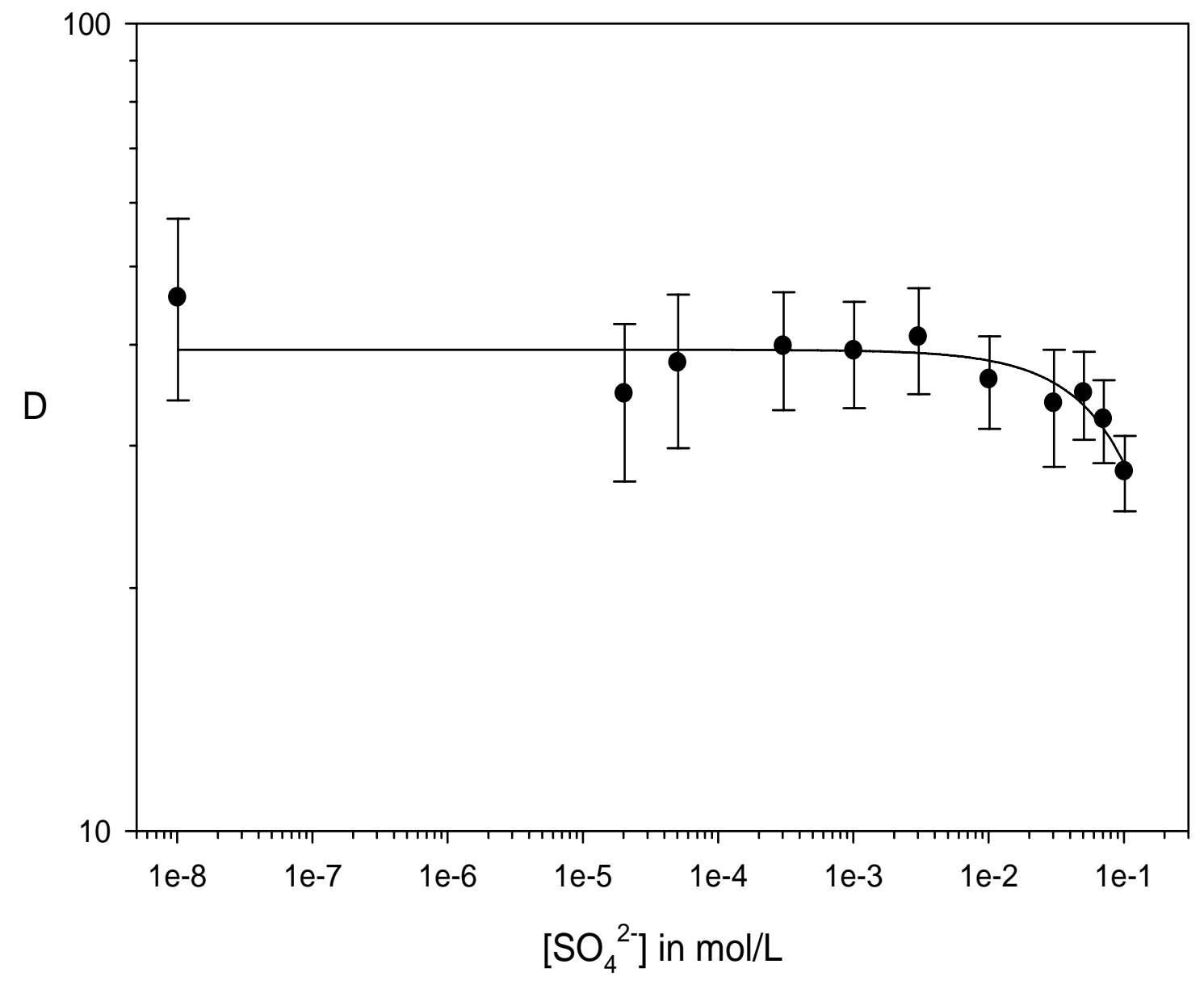


Figure 3: Study of the oxidation of Species II in a biphasic aqueous/Dowex-50WX8 system. $p H$ is varied using $\mathrm{HClO}_{4}\left(\mathrm{~A}=0.01 \mathrm{~mol} / \mathrm{L} \mathrm{HClO}_{4}, \mathrm{~B}=0.013 \mathrm{~mol} / \mathrm{L} \mathrm{HClO} 4, \mathrm{C}=0.1 \mathrm{~mol} / \mathrm{L}\right.$ $\left.\mathrm{HClO}_{4}, \mathrm{D}=0.3 \mathrm{~mol} / \mathrm{L} \mathrm{HClO}_{4}\right)$. The lines correspond to the calculation performed with CHESS using the parameters given in Table 3.

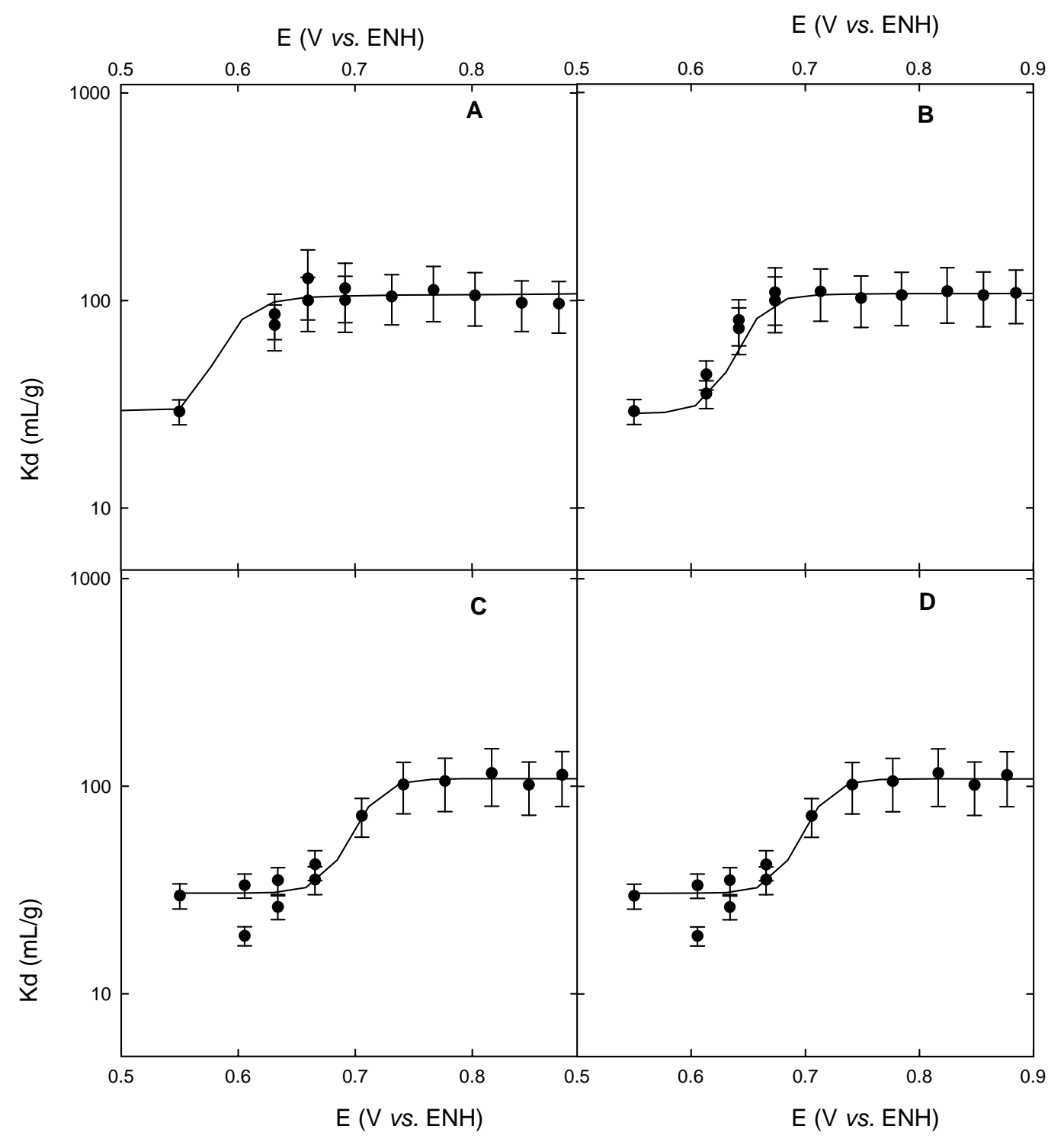


Figure 4 : Apparent $E^{\circ}{ }^{\circ}$ values deduced from Figure 3 plotted as a function of $p H$ together with literature data (Circle: this work, Triangle: Visser et al. ${ }^{41}$, Square: Cavallero et al. ${ }^{3}$ ).

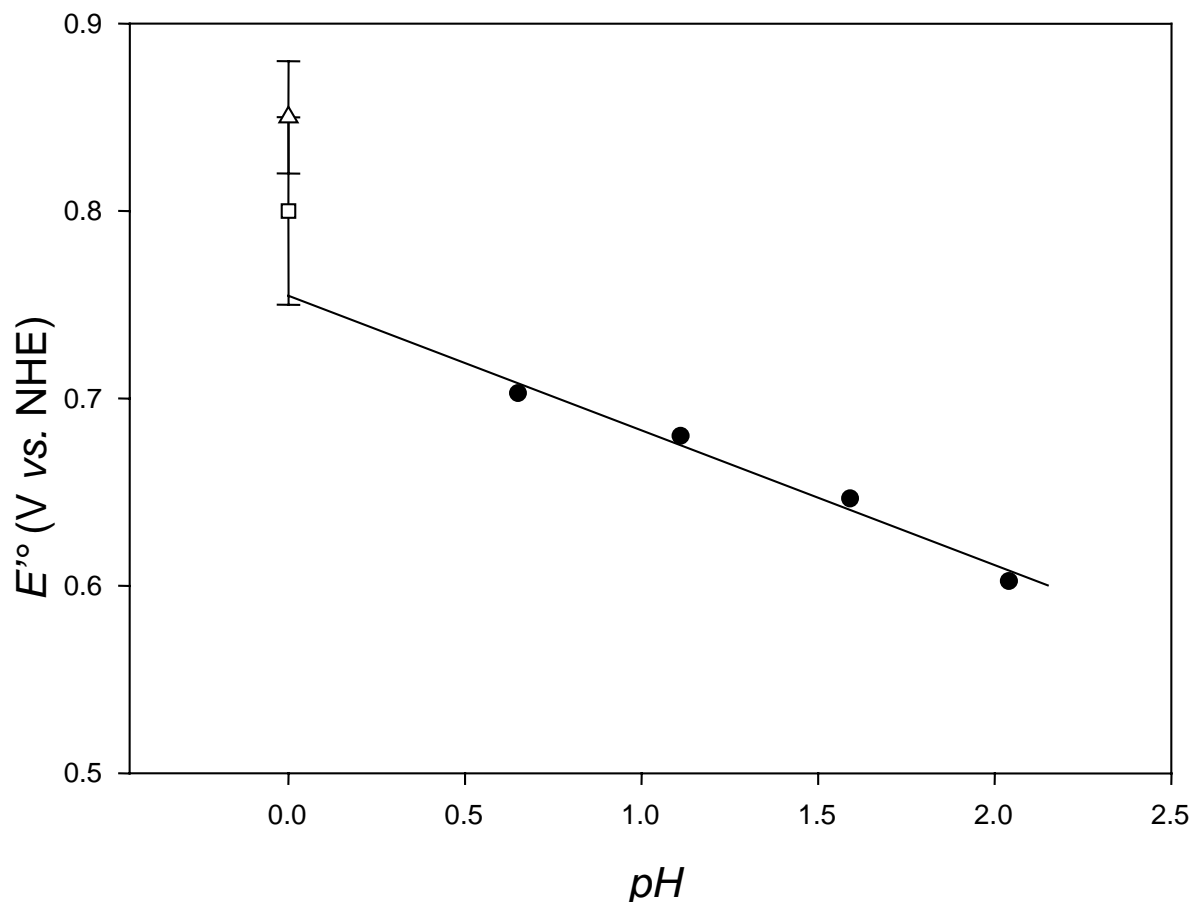




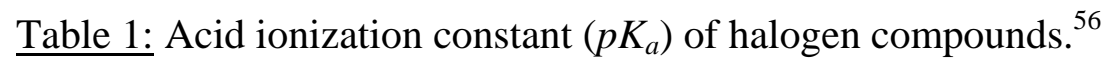

\begin{tabular}{crlc}
\hline Species & \multicolumn{2}{c}{ Equilibrium } & $p K a$ \\
\hline $\mathrm{F}^{-} / \mathrm{HF}$ & $\mathrm{HF} \square$ & $\mathrm{F}^{-}+\mathrm{H}^{+}$ & 3.18 \\
$\mathrm{Cl}^{-} / \mathrm{HCl}$ & $\mathrm{HCl} \square$ & $\mathrm{Cl}^{-}+\mathrm{H}^{+}$ & -7.00 \\
$\mathrm{Br}^{-} / \mathrm{HBr}$ & $\mathrm{HBr} \square$ & $\mathrm{Br}^{-}+\mathrm{H}^{+}$ & -9.00 \\
$\mathrm{I}^{-} / \mathrm{HI}$ & $\mathrm{HI} \square$ & $\mathrm{I}^{-}+\mathrm{H}^{+}$ & -11.00 \\
\hline
\end{tabular}

Table 2: Computed standard reduction potentials (V vs. NHE).

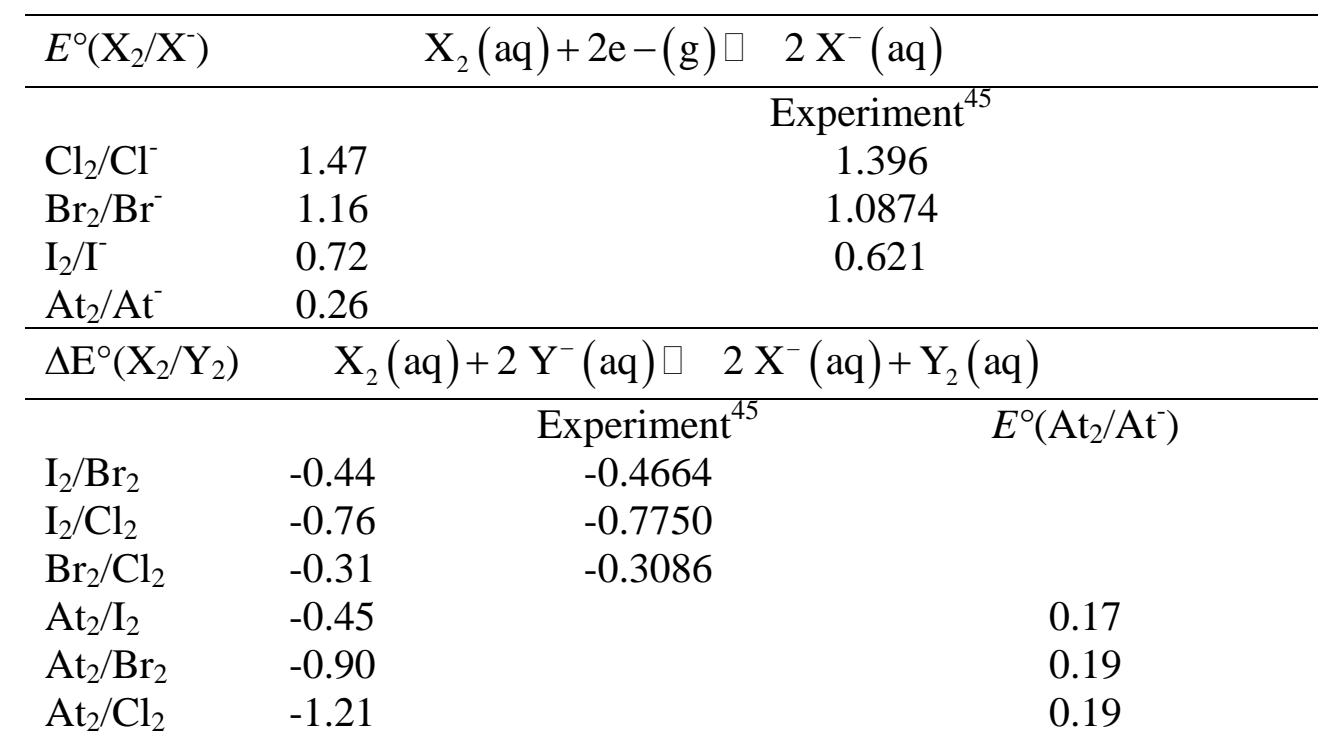

Table 3: List of equilibria considered for modeling astatine behavior and their associated thermodynamic constants at zero ionic strength, $298.15 \mathrm{~K}$ and $1 \mathrm{~atm}$.

\begin{tabular}{|c|c|c|c|}
\hline Species & Equilibrium & Log K & Figure \\
\hline $\mathrm{At}^{+} / \mathrm{At}^{-}$ & $\mathrm{At}^{+}+\mathrm{H}_{2} \mathrm{O} \square \quad \mathrm{At}^{-}+2 \mathrm{H}^{+}+\frac{1}{2} \mathrm{O}_{2}$ & -30.96 & $1 \& 2$ \\
\hline $\mathrm{At} / \mathrm{At}^{-}$ & $\mathrm{At}+\frac{1}{2} \mathrm{H}_{2} \mathrm{O} \square \quad \mathrm{At}^{-}+\mathrm{H}^{+}+\frac{1}{4} \mathrm{O}_{2}$ & -15.48 & 1 \\
\hline $\mathrm{At}^{+} / \mathrm{SO}_{4}{ }^{2-}$ & $\mathrm{At}^{+}+\mathrm{SO}_{4}^{2-} \square \quad \mathrm{At}\left(\mathrm{SO}_{4}\right)^{-}$ & 1.00 & 2 \\
\hline $\mathrm{At}^{+} / \mathrm{AtO}^{+}$ & $\mathrm{At}^{+}+\frac{1}{2} \mathrm{O}_{2} \square \quad \mathrm{AtO}^{+}$ & 17.83 & 3 \\
\hline
\end{tabular}




\section{REFERENCES}

(1) Zalutsky, M. R.; Reardon, D. A.; Akabani, G.; Coleman, R. E.; Friedman, A. H.; Friedman, H. S.; McLendon, R. E.; Wong, T. Z.; Bigner, D. D. J. Nucl. Med. 2008, 49, 30-38.

(2) McDevitt, M. R.; Sgouros, G.; Finn, R. D.; Humm, J. L.; Jurcic, J. G.; Larson, S. M.; Scheinberg, D. A. Eur. J. Nucl. Med. 1998, 25, 1341-1351.

(3) Cavallero, A.; Roessler, K. Radiochim. Acta 1989, 47, 113-117.

(4) Meyer, G. Chromatographie trägerfreier anorganischer formen von jod-123 und astat-211 und ihre verwendung zur halogenierung von uracil and desoxyuridin, University of Jülich, July 1974.

(5) Roessler, K.; Tornau, W.; Stoecklin, G. J. Radioanal. Chem. 1974, 21, 199209.

(6) Berei, K.; Vasaros, L. Astatine Compounds, 8th ed.; Springer-Verlag: Berlin, 1985.

(7) Hung, T. K.; Milanov, M.; Rosch, F.; Khalkin, V. A. Radiochim. Acta 1989, 47, 105-108.

(8) Appelman, E. H. J. Am. Chem. Soc. 1961, 83, 805-807.

(9) Visser, G. W. Radiochim. Acta 1989, 47, 97-103.

(10) Henriksen, G.; Messelt, S.; Olsen, E.; Larsen, R. H. Appl. Radiat. Isot. 2001, $54,839-844$.

(11) Yordanov, A. T.; Pozzi, O.; Carlin, S.; Akabani, G.; Wieland, B. W.; Zalutsky, M. R. J. Radioanal. Nucl. Chem. 2004, 262, 593-599.

(12) Alliot, C.; Cherel, M.; Barbet, J.; Sauvage, T.;Montavon, G. Radiochim. Acta 2009, 97, 161-165.

(13) Groppi, F.; Bonardi, M. L.; Birattari, C.; Menapace, E.; Abbas, K.; Holzwarth, U.; Alfarano, A.; Morzenti, S.; Zona, C.; Alfassi, Z. B. Appl. Radiat. Isot. 2005, 63, 621-631.

(14) Fu-Chiung, W.; Norseev, Y. V.; Khalkin, V. A. Radiokhimiya 1963, 5, 351355.

(15) Appelman, E. H. The Radiochemistry of Astatine, Argonne National Laboratory, 1960.

(16) Champion, J.; Alliot, C.; Huclier, S.; Deniaud, D.; Asfari, Z.; Montavon, G. Inorgan. Chim. Acta 2009, 362, 2654-2661.

(17) Van Der Lee, J.; De Windt L. J. Contam. Hydrol. 2001, 47, 265-282.

(18) SigmaPlot 10 Scientific Graphing Software, Systat Software: Point Richmond, 1993.

(19) Colston, B. J.; Robinson, V. J. J. Environ. Radioactiv. 1995, 29, 121-136.

(20) Peterson, K.A.; Figgen, D.; Goll, E.; Stoll, H.; Dolg, M. J. Chem. Phys. 2003, $119,11113-11123$.

(21) Mitin, A. V.; van Wullen, C. J. Chem. Phys. 2006, 124, 64305-64307.

(22) Bylaska, E. J.; de Jong, W. A.; Kowalski, K.; Straatsma, T. P.; Valiev, M.; Wang, D.; Apra, E.; Windus, T. L.; Hirata, S.; Hackler, M. T.; Zhao, Y.; Fan, P.-D.; Harrison, R. J.; Dupuis, M.; Smith, D. M. A.; Nieplocha, J.; Tipparaju, V.; Krishnan, M.; Auer, A. A.; Nooijen, M.; Brown, E.; Cisneros, G.; Fann, G. I.; Fruchtl, H.; Garza, J.; Hirao, K.; Kendall, R.; Nichols, J. A.; Tsemekhman, K.; Wolinski, K.; Anchell, J.; Bernholdt, D., Borowski, P.; Clark, T.; Clerc, D.; Dachsel, H.; Deegan, M.; Dyall, K.; Elwood, D.; Glendening, E.; Gutowski, M.; Hess, A.; Jaffe, J.; Johnson, B.; Ju, J.; Kobayashi, R.; Kutteh, R.; Lin, Z.; Littlefield, R.; Long, X.; Meng, B.; Nakajima, T.; Niu, S.; Pollack, L.; Rosing, M.; Sandrone, G.; Stave, M.; Taylor, H.; Thomas, G.; van Lenthe, J.; Wong, A.; Zhang, Z. NWChem A 
Computational Chemistry Package for Parallel Computers, Version 5.0, Pacific Northwest National Laboratory: Washington, 2006.

(23) Cho, W. K.; Choi, Y. J.; Lee, Y. S. Mol. Phys. 2005, 103, 2117-2122.

(24) Choi, Y. J.; Lee, Y. S. J. Chem. Phys. 2003, 119, 2014-2020.

(25) Lee, H. S.; Cho, W. K.; Choi, Y. J.; Lee, Y. S. Chem. Phys. 2005, 311, 121127.

(26) Becke, A. D. J. Chem. Phys. 1993, 98, 5648-5653.

(27) Lee, C.; Yang, W.; Parr, R. G. Phys. Rev. B 1988, 37, 785-789.

(28) Stephens, P. J.; Devlin, F. J.; Chabalowski, C. F.; Frisch, M. J. J. Phys. Chem. 1994, 98, 11623-116627.

(29) Peterson, K. A.; Shepler, B. C.; Figgen, D.; Stoll, H. J. Phys. Chem. A 2006, $110,13877-13883$.

(30) Woon, D. E.; Dunning Jr., T. H. J. Chem. Phys. 1993, 98, 1358-1371.

(31) Frisch, M. J.; Trucks, G. W.; Schlegel, H. B.; Scuseria, G. E.; Robb, M. A.; Cheeseman, J. R.; Montgomery Jr., J. A.; Vreven, T.; Kudin, K. N.; Burant, J. C.; Millam, J. M.; Iyengar, S. S.; Tomasi, J.; Barone, V.; Mennucci, B.; Cossi, M.; Scalmani, G.; Rega, N.; Petersson, G. A.; Nakatsuji, H.; Hada, M.; Ehara, M.; Toyota, K.; Fukuda, R.; Hasegawa, J.; Ishida, M.; Nakajima, T.; Honda, Y.; Kitao, O.; Nakai, H.; Klene, M.; Li, X.; Knox, J. E.; Hratchian, H. P.; Cross, J. B.; Bakken, V.; Adamo, C.; Jaramillo, J.; Gomperts, R.; Stratmann, R. E.; Yazyev, O.; Austin, A. J.; Cammi, R.; Pomelli, C.; Ochterski, J. W.; Ayala, P. Y.; Morokuma, K.; Voth, G. A.; Salvador, P.; Dannenberg, J. J.; Zakrzewski, V. G.; Dapprich, S.; Daniels, A. D.; Strain, M. C.; Farkas, O.; Malick, D. K.; Rabuck, A. D.; Raghavachari, K.; Foresman, J. B.; Ortiz, J. V.; Cui, Q.; Baboul, A. G.; Clifford, S.; Cioslowski, J. ; Stefanov, B. B.; Liu, G.; Liashenko, A.; Piskorz, P.; Komaromi, I.; Martin, R. L.; Fox, D. J.; Keith, T.; AlLaham, M. A.; Peng, C. Y.; Nanayakkara, A.; Challacombe, M.; Gill, P. M. W.; Johnson, B.; Chen, W.; Wong, M. W.; Gonzalez, C.; Pople J. A. Gaussian 03, Revision C.02, Gaussian Inc.: Wallingford CT, 2004. 669-681.

(32) Cossi, M.; Rega, N.; Scalmani, G.; Barone, V. J. Comput. Chem. 2003, 24,

(33) Barone, V.; Cossi, M. J. Phys. Chem. A 1998, 102, 1995-2001.

(34) Takano, Y.; Houk, K. N. J. Chem. Theory Comput. , 1, 70-77.

(35) Barone, V.; Cossi, M.; Tomasi, J. J. Chem. Phys. 1997, 107, 3210-3221.

(36) Clementi, E.; Raimondi, D. L.; Reinhardt, W.P. J. Chem. Phys. 1967, 47, 1300 -

1307.

(37) Cordero, B.; Gomez, V.; Platero-Prats, A. E.; Revés, M.; Echeverría, J.; Cremades, E.; Barragán, F.; Alvarez S. Dalton Trans. 2008, 21, 2832-2838.

(38) Mantina, M; Chamberlin, A. C.; Valero, R.; Cramer, C. J.; Trulhar, D. G., J. Phys. Chem. A 2009, 113, 5806-5812.

(39) Cramer, C. J. Essentials of Computational Chemistry : Theories and Models; $2^{\text {nd }}$ ed., J. Wiley and Sons: Chichester, 2004.

(40) Johnson, G. L.; Leininger, R. F.; Segre, E. J. Chem. Phys. 1949, 17, 1-10.

(41) Visser, G. W.; Diemer, E. L. Radiochim. Acta 1983, 33, 145-151.

(42) Cavallero, A.; Roessler, K. Radiochim. Acta 1989, 47, 109-113.

(43) Bartmess, J. E. J. Phys. Chem. 1994, 98, 6420-6424.

(44) Kelly, C. P.; Cramer, D C. J., Truhlar, G. J. Phys. Chem. B 2006, 110, 1606616081.

(45) Bard, A. J.; Parsons, R.; Jordan, J. Standard Potentials in Aqueous Solution, International Union of Pure Applied Chemistry, Marcel Dekker Inc: New York, 1985.

(46) Milanov, M.; Doberenz, V.; Khalkin, V. A.; Marinov, A. J. Radioanal. Nucl. Chem. 1984, 83, 291-299. 
(47) Milanov, M.; Doberenz, W.; Marinov, A.; Khalkin, V. A. J. Radioanal. Nucl. Chem. 1984, 82, 101-109.

(48) Lindegren, S.; Andersson, H.; Back, T.; Jacobsson, L.; Karlsson, B.; Skarnemark, G. Nucl. Med. Biol. 2001, 28, 33-39.

(49) Dreyer, I.; Dreyer, R.; Chalkin, V. A Radiochem. Radioanal. Letters 1978, 36, 389-398.

(50) Golovkov, N.A.; Gromova, I. I.; Janicki, M.; Norseyev, Y.V.; Sandukovsky, V.G.; Vasaros, L. Radiochem. Radioanal. Letters 1980, 44, 67-78.

(51) Appelman, E. H.; Sloth, E. N.; Studier, M. H. Inorg. Chem. 1966, 5, 766-769.

(52) Dreyer, I.; Dreyer, R.; Chalkin, V. A.; Milanov, M. Radiochem. Radioanal. letters 1979, 40, 145-154.

(53) Dreyer, R.; Dreyer, I.; Pfeiffer, M.; Rosch, F. Radiochem. Radioanal. Letters 1982, 55, 207-214.

(54) Norseyev, Y. V.; Khalkin, V. A. J. Inorg. Nucl. Chem. 1968, 30, 3239-3243.

(55) Dreyer, R.; Dreyer, I.; Rosch, F.; Beyer, G. J. Radiochem. Radioanal. Letters 1982, 54, 165-175.

(56) Fraústo da Silva J. J. R. The Natural Selection of the Chemical Elements: The Environment and Life's Chemistry; Oxford University Press, 1997. 